\title{
Online Course Quality Assurance: Development of a Quality Checklist
}

\author{
Steven J. McGahan, MSEd \\ Assistant Director for Technology \\ Instructional Design Specialist \\ University of Nebraska at Kearney \\ Christina M. Jackson, APR, EdD \\ Assistant Professor of Communication \\ University of Nebraska at Kearney \\ Karen Premer, MSEd \\ Assistant Director for Marketing \\ Instructional Design Specialist \\ University of Nebraska at Kearney
}

The University of Nebraska at Kearney's Online Course Checklist is the main instrument for assessing the quality of online courses at UNK. A number of issues were faced when developing and deploying this quality assurance checklist at a small four-year university. The process including development, implementation, and revision is discussed along with the need for faculty buy-in. Special considerations included how to assess the quality of an online course while ensuring academic freedom in accordance with a union contract. The purpose of this case study is to provide a roadmap for institutions that are developing an instrument of their own.

The number of students taking online courses continues to grow. According to a recent study, "Grade change: Tracking online education in the United States," by the Online Learning Consortium, 33.5\% of higher education students in the fall of 2012 took an online course (Allen \& Seaman, 2014). A total of 7.1 million students were taking at least one online course, an increase of 411,000 students from the previous year (Allen \& Seaman, 2014). This represents a $6.1 \%$ increase (Allen \& Seaman, 2014). Almost two-thirds of Chief Academic Officers (CAO) believe that it is very likely that students at higher education institutions will take at least one online course in the next five years. In addition, $65.9 \%$ of CAOs also believe online education is a critical piece in the long-term strategy for their institutions (Allen \& Seaman, 2014).

As the number of courses delivered online has continued to grow, knowledge of what constitutes a successful online course has increased as well (Khan \& Chishti, 2012; Singer, 2008). These include, but are not limited to, navigation (Chen, 2010; Graf, Luit, \& Kinshuk, 2010; Metros \& Hedberg, 2002; Sung \& Mayer, 2012), the inclusion of rich media components (Borgemenke, Holt, \& Fish, 2013; Havice, Davis, Foxx, \& Havice, 2010; Schiefelbein, 2011) and opportunities for collaboration with peers and the instructor (Brindley, Blaschke, \& Walti, 2009; Gonzalez, 2010; Orde et al., 2001).

Choices in course design have a far-reaching impact. The best medium through which to communicate within the confines of the learning management system must be selected (Schiefelbein, 2011). Planned flexibility in navigation helps learners adapt to the environment based on their cognitive styles (Chen, 2009). Course design impacts student engagement and success (Murray, Perez, Geist, Hedrick, \& Steinback, 2012), with scaffolding helping to increase student engagement (Cho \& Cho, 2013) and learner satisfaction (Havice et al., 2010). Online videos are growing in importance as ease of delivery continues to improve (DeCesare, 2014). 
The success of an online course is basedin part-on the quality of instructional design. Faculty members are subject matter experts, but may not have the pedagogical background and instructional design skills necessary to develop quality online courses (Caplan, 2004). By helping them understand and apply best practices in online course creation and delivery, there is an increased level of success for faculty building courses and the learners for whom they build the class (Murray et al., 2012).

To address this, institutions have adopted various strategies to provide support for faculty members developing online courses. This may come in the form of course shells or templates (Miller, 2012; "With Seton Hall's Course Template, All Faculty Are Champions," 2011). Other institutions create programs that provide faculty instructional design support ("Instructional Designer's Guide to Working with Faculty," 2006; Lorenzetti, 2009) to help build competency. Models where faculty focus on course design within their own discipline, rather than focusing on higherlevel instructional design (Power, 2008), have proven effective at some institutions.

Some institutions focus on online course design from the institutional level, focusing on minimizing institutional barriers such as "compensation and time; organizational change; and technical expertise, support, and infrastructure" (Orr, Williams, \& Pennington, 2009, p. 258). Others approach course development by creating an institutional infrastructure where online courses are an essential component of the institution's mission while shifting programs to online delivery (Hillman \& Corkery, 2010). Online courses take more time to develop than traditional face-to-face courses (Rahm-Barnett \& Donaldson, 2008). The amount of time and effort spent in developing these courses can cause pieces to be missed.

Regardless of the process or approach, quality assurance can be used to build confidence in the process and ensure that key factors leading to the success of the online course are incorporated into the course structure. Developing standard process and procedures aids in identifying quality standards ("Holding on to quality during rapid expansion", 2011; Hosie, Schibeci, \& Backhaus, 2005). The quality assurance instrument provides a blueprint to follow during the review process, helping to streamline the review process.

Prebuilt quality control evaluation instruments such as Maryland Online's Quality Matters (QM) rubric, the Illinois Online Network's (ION) Quality Online Course Initiative rubric (QOCI), and California State University, Chico's Rubric for Online Instruction (ROI) may be adopted, while other institutions may consider building an evaluation instrument based on specific institutional needs. Such was the case at the University of Nebraska at Kearney where an in-house quality assurance instrument was developed. The purpose of this case study is to review the development, implementation, and revision process for UNK's Online Course Checklist and to provide a roadmap for any institution that is developing an instrument of their own.

\section{Background}

The University of Nebraska at Kearney (UNK) is a rural four-year university in the Great Plains. The 2013-14 total enrollment at UNK was 7,100 students with approximately $77 \%$ of these being undergraduates. eCampus is a UNK support department for online, blended, and videoconference courses. The department currently consists of nine full-time positions, including a director, three instructional designers, two video engineers, a marketing specialist, and two office associates. These nine positions support the approximately 100 faculty who teach online each semester.

Prior to 2004, no training was offered to faculty who taught online. By 2005, two instructional designers had been hired, and a training course was being offered once a year to faculty who wished to improve their online teaching. Prior to 2006 , online courses were not evaluated at UNK. Faculty created and taught online 
courses with no evaluation process. As online learning continued to grow, so did the need for quality assurance. With the rapid growth of online courses at UNK, the next logical step was to create a way to ensure that best practices from the training course were being used in online courses. "When managing multiple simultaneous course development projects, online development units can identify quality standards by taking advantage of standard processes and procedures" ("Holding on to quality during rapid expansion", 2011, p. 5). An evaluation instrument would show where "design and delivery are sound" and "identify deficient aspects" within courses (Hosie et al., 2005, p. 545).

Faculty at UNK develop their own courses, with the instructional designers available for consultation and to create media and interactive pieces that would be too difficult for the faculty to create on their own. This process has proven to be the most efficient way to support such a large number of courses with only three instructional designers.

The instructional design team referenced in this article consisted of two people. Steven McGahan and Karen Premer were, at the time when the instrument was developed, the only two instructional designers on the UNK campus. It should be noted that the process described in this case study was informal, until the instrument was turned over for review by the committees. The instructional design team was still relatively new, and the development of the instrument was a bottomup process.

UNK had been offering online courses since 2000, when there were two courses with a total enrollment of 35 students. The first instructional designer was hired in December of 2003, and then a second was hired in October of 2004 to meet the growing demand for support for online courses. In the summer of 2006, online courses were the fastest growing segment of UNK course and program offerings. In the summer of 2006, there were a total of 52 faculty, offering 78 courses (undergraduate and graduate) with a total duplicated enrollment of 1,558. This substantial growth in online courses at UNK was one factor in the need for a way to assess the quality of courses.

With two instructional designers to consult and assist faculty in their course development and a solid training program in place, the next logical step was to either find or develop an instrument to ensure the quality of the courses being developed at UNK. Instructional designers attended the Illinois Online Network's Faculty Summer Institute (FSI) to find new ideas and technology for use at UNK. The idea to create a quality assurance instrument began at FSI.

One of the sessions was on the Quality Online Course Initiative Rubric, developed by the Illinois Online Network. This instrument rated the quality of online courses using many different criteria and allowed faculty to see where their courses might need improvement. Upon returning to UNK, the instructional designers decided to look into using one of the outside assessment instruments. The process began with the initial research into the rubrics available from other universities and initiatives.

\section{Initial Research}

Once the decision was made to apply a course quality instrument to UNK online courses, the first step was to review various instruments available to look for a prebuilt quality control evaluation that could be implemented immediately. With several options to choose from, the instructional designers narrowed the choices to three that were the most viable options and best fit the needs of the faculty: Maryland Online's Quality Matters (QM) rubric, the Illinois Online Network's (ION) Quality Online Course Initiative rubric (QOCI), and California State University, Chico's Rubric for Online Instruction (ROI). 


\section{Quality Matters}

The Quality Matters (QM) rubric, developed by Maryland Online, is one of the most well-known course evaluation rubrics in online education. This was the natural starting-point to begin investigating off-the-shelf evaluation rubrics for use at UNK. The QM rubric covers several areas of criteria, including course overview and introduction, learning objectives, assessment and measurement, instructional materials, learner interaction, and engagement, course technology, learner support, and accessibility ("Quality Matters rubric," n.d.).

The official, fee-based process was reviewed first. The official process uses external reviewers to review a course. A QM reviewer assigns points based on the separate criteria that are weighted on a three-point scale. The weighted points denote the importance of each criterion, and the criteria that have a value of three points are all required to pass the review process.

Quality Matters had some distinct advantages. It was a large and comprehensive course evaluation rubric. The QM rubric covered several critical areas that would later be used as a starting point for some of the UNK course evaluation rubric. It also showed levels of competency for each criterion and weighted them according to their importance to an online course.

The disadvantages of the QM rubric were evident early in the review process. The complexity of the rubric and grading system precluded being used to assess online courses at UNK. The rubric also required a significant time commitment to complete, and there were not enough staff members to properly execute this grading rubric. Cost factors also contributed to not being able to use the official Quality Matters course evaluation process, as QM uses a fee-based system for their official reviews ("Guidelines from the Quality Matters rubric", 2009).

The use of the QM rubric would have been problematic because of concerns regarding academic freedom and compliance with the union contract governing UNK faculty. The academic freedom policy does not allow the grading of courses on a scale without some intervention by the Faculty Senate to approve this process. While this factor was unknown during the initial review (this concern would be brought up during the faculty review process), a way to evaluate the courses without assigning any points or a scale to the process was needed.

\section{Quality Online Course Initiative}

The Quality Online Course Initiative Rubric (QOCI) is an instrument developed by the Illinois Online Network. Much like the Quality Matters rubric, QOCI is a comprehensive rubric that covers several areas in the development of online courses, including instructional design; communication, interaction, and collaboration; student evaluation and assessment; learner support and resources; web design; and course evaluation ("Quality Online Course Initiative rubric", n.d.). The instrument uses a four-point grading system to evaluate criteria in each of the areas for quality. Unlike the QM rubric, QOCI is free to use, download, and modify for use at any institution (Patterson Lorenzetti, 2007), as it is licensed under a Creative Commons copyright ("Quality Online Course Initiative rubric", n.d.).

Much like the other instruments, this comprehensive rubric did a good job at evaluating the quality of a course. Its comprehensive nature was a positive, just like QM. It covered many areas that are critical to a quality online course. Unlike $\mathrm{QM}$, no complex grading system was in the rubric, and therefore, was easier to use.

Again, there were disadvantages to QOCI. Much like Quality Matters, the instrument was rather long and took significant time to complete. QOCI comes in at 23 pages without instructions. The amount of time necessary to complete the rubric for a course would have been difficult to manage with the number of new courses being developed at UNK. Had QOCI been adopted, faculty and instructional designers would have been spending most of their time going through the rubric for 
each of the courses, and QOCI would not have been able to offer other training opportunities and multimedia development to the faculty.

Again, the issues of evaluating faculty work and academic freedom would prohibit the adoption of this instrument. Information on how these issues were addressed will be presented at a later point in this discussion.

\section{Rubric for Online Instruction}

The Rubric for Online Instruction (ROI) is an instrument developed at California State University, Chico. The immediate opinion of the ROI was that at seven pages, it was far more compact than the other two instruments. Although it still covered many of the same issues in development, it would not take as much time to review a course as the other rubrics that were examined. The ROI covered six areas of development, including learner support and resources; online organization and design; instructional design and delivery; assessment and evaluation of student learning; innovative teaching with technology; and faculty use of student feedback ("Rubric for Online Instruction", n.d.). It was the easiest to use, and the time necessary to review a course was the shortest. ROI is also free to use and modify as it is available under a Creative Commons license ("Rubric for Online Instruction", n.d.).

Of the three instruments that were reviewed, the Rubric for Online Instruction was the least comprehensive. While the time factor was important, it was still necessary to take a comprehensive look at the aspects of a course that were seen as the most important. The ROI was a little too simple for use at UNK. While the categories were fairly comprehensive, specifics within each were too broad and did not point out certain key areas that were important in UNK courses. The number of criteria in each of the six sections ranged from three to five, for a total of 25 criteria.

One other drawback was the use of a three-point scale to evaluate each criterion. The ROI still used a rubric system that grouped each criterion into one of three classifications. This would certainly cause issues with the evaluation of faculty teaching and development. Again, it was necessary to use an instrument that did not appear to rate or rank the courses or faculty.

\section{Instrument Development}

After the determination was made that none of the three existing instruments met the specific needs of the UNK faculty and campus, it was decided that a specific UNK instrument was needed. Several factors needed to be addressed in an instrument for use on the UNK campus. These included ease of use, addressing multiple skill levels, encouraging rich media, and compliance with the faculty union contract.

\section{Development of the Instrument Criteria}

Culling from the large number of criteria that make a quality online course is not an easy task. The instructional designers reviewed several off-the-shelf instruments and current research on online course quality to determine what criteria would be included in the final instrument. Research shows that there are several factors to consider when developing a successful online course. Some of the major categories that were included were ease of course navigation, collaboration and interaction, encouraging rich media, multiple modes of learning and assessment, and Americans with Disabilities Act considerations. The instructional designers decided to leave out the more esoteric elements such as teaching style from the instrument, since these elements would be difficult to quantify. 


\section{Ease of Course Navigation}

Course navigation can easily turn great content into a bad learning experience. Students need to feel comfortable in moving around a course, and a confusing navigation system will cause issues with learning. It seems a simple idea; however, poor navigational structure can be easily overlooked. Emphasis needs to be placed on how learners interact with the course interface. There is a need for clear design in navigation and interface and for less complexity in online courses (Metros \& Hedberg, 2002). Students need a well-structured and organized course to be successful in online courses (Hoffman, 2012).

As with writing, a course developer can become so close to their own content that they are not able to see the issues present with the finished product. The course interface must be intuitive and facilitate learning and interaction between the learners and the content, instructor, and other students (Metros \& Hedberg, 2002). What seems simple to use to the faculty member can feel like an impassible maze to the students. Course shells can improve navigation, leading to improved engagement (Miller, 2012).

Considering the learning styles of students may also reduce effort as well (Graf et al., 2010). Based on the way learners view the course structure, they can get lost in the learning management system (Sung \& Mayer, 2012). The demands of navigation can cause a cognitive overload, preventing them from learning the content. The inability to find content, assignments, or links to help resources may frustrate students in a course (Sung \& Mayer, 2012). Navigation behaviors differ based on cognitive style (Chen, 2010).

Several criteria were chosen to reflect the importance of navigation ("eCampus online," 2014); these include:

- A concise list of units/modules that will be completed in the course is provided;

- A concise list of activities that will be completed in the course is provided;

- The navigational instructions make the organization of the course easy to understand;

- The content is arranged in a manner that enables learners to achieve the stated goals;

- Resources and materials are easily accessible to and usable by the learners;

- Consistent layout design is used throughout;

- Scrolling is minimized by "chunking" materials;

- Navigation cues are present and identifiable (i.e., Start Here).

\section{Collaboration and Interaction}

Collaboration and interaction with the instructor, the content, and other students is important in helping the students feel connected to the course (Poole, 2000). Engaged students tend to be more successful students (Poole, 2000).

Requiring interaction among students and between students and the instructor using coordinated group activities, such as discussion boards and synchronous class sessions, can be very effective for learning (Orde et al., 2001). The formation of small collaborative groups can lead to deeper learning (Brindley et al., 2009). Use of these types of interaction and collaboration, if done correctly, can facilitate higher-level learning, and students can broaden their knowledge by reflecting on their own experiences and the knowledge and experiences of the other students and the instructor (Gonzalez, 2010). These types of tools can also be used solely to present information and course content (Gonzalez, 2010).

Collaboration and interaction were important aspects that needed to be addressed in the instrument. Not only do these create a sense of community in a course, but they also require that students learn along a specific timeline. In order 
to participate in the course, students must interact with each other and the instructor at specific times during the course.

Several criteria were chosen to reflect the importance of collaboration and interaction ("eCampus online," 2014); these include:

- The instructor's role in discussion activities is clearly defined. (Facilitate, Clarify, Question, Observe, etc.).

- Learning activities are developed to stimulate communication and/or collaboration between student and instructor.

- Discussions are organized in specific forums and/or threads.

- The requirements for course interaction are clearly articulated.

- A statement is provided explaining when students should receive feedback for assignments, exams, discussion boards, and emails.

- Learning activities are developed to stimulate communication and/or collaboration between student and student.

- The course offers separate forums for Technical Questions, Content Related Questions, and Community Communication.

- A rubric defining student participation is provided.

\section{Encouraging Rich Media}

Rich media is an important part of online courses. Rich media can provide learners with nuanced messages through verbal and non-verbal cues, as well as "spoken and written word, and visual symbols and images" (Schiefelbein, 2011, p. 1). Simple text-based courses may have been standard in the early days of online education; however, students expect more from their online courses than reading and taking tests or writing papers. The integration of images, charts and graphs, audio, video, and interactive learning objects creates more interaction between the student and the content. In some cases, the inclusion of media itself isn't as important as the sense of control the learner feels in the environment (Borgemenke et al., 2013). The ability to control playback of rich media may help in "promoting greater reinforcement of course content and student engagement in the course" (Havice et al., 2010, p. 57; Lee \& Chan, 2007).

When the instrument was originally written, online video was still in its infancy, and most courses at UNK did not use much in the way of visual elements. It is sometimes hard to believe how quickly technology changes the way instruction and content are handled. Images and audio were the common rich media at that point in time. Because of this, the technical aspects were the primary focus of the instrument.

The focus was not to make the courses pretty, but to add media that differentiated important areas and helped to engage the students in the course. As video was one of the more advanced aspects, it was necessary to steer these additions in the correct direction. The main purpose of the video should be to deliver content and methods of instruction, not to make the course more visually appealing (Castle \& McGuire, 2010). This is not to say that these elements can only be used for presenting content. Increasing the presence and establishing the personality of the instructor can be achieved as well. Both synchronous and asynchronous video communication has an impact on students' view of the presence of the instructor and helps them perceive the instructor as a real person (Borup, West, \& Graham, 2012).

Several criteria were chosen to reflect the importance of rich media ("eCampus online," 2014); these include:

- Technical Requirements - no specialized software or hardware is needed, and all players are provided or available freely for download;

- Images added to the course are clear;

- Image files are optimized for efficient loading; 
- Audio materials added to the course are clear;

- Audio file length is adequate to meet the goals of the activity without adding unnecessary information;

- Video materials added to the course are clear;

- Video file length is adequate to meet the goals of the activity without adding unnecessary information;

- The selection and use of tools and media supports the learning objectives of the course;

- Selection and use of tools and media enhances learner interactivity.

\section{Development Factors for the Instrument}

In addition to focusing on the criteria for the instrument, it was necessary to consider specific issues that would arise when faculty at UNK tried to use the instrument. Some of these issues are common to most secondary educators; others were specific to the UNK faculty. When developing an online course evaluation, it is necessary to take into account not only what will be evaluated, but also how the instrument will function in the hands of those who use it. This meant looking at three specific issues: ease of use of the instrument, use by faculty with multiple skill levels, and compliance with the University of Nebraska at Kearney Education Association (UNKEA) Faculty Contract.

\section{Ease of Instrument Use}

First and foremost, the developed instrument needed to be easy for faculty to use. The main issue discovered when reviewing the off-the-shelf instruments was that the instruments were complex and required time-intensive evaluation. The instructional designers determined that they needed a rubric that would be both comprehensive and easy to use; the final instrument could be no more than three pages long and be easy enough to use as a self-assessment.

In order to get faculty on board with using the instrument, it needed to be simple enough to use without the assistance of an instructional designer. An instrument like Quality Matters or the Quality Online Course Initiative rubric requires a great deal of time and effort to complete successfully. These instruments included some instructional design principles that may have been unfamiliar to some faculty at UNK. Building and teaching an online course is time-consuming enough without adding a long process to decide whether the course is up to a

When developing an online course evaluation, it is necessary to take into account not only what will be evaluated, but also how the instrument will function in the hands of those who use it. certain standard of quality. The QM rubric has 41 separate quality criteria on one sheet; and, while this may seem like a quick system to use for the review of a course, it also prescribes weighted measures for each criterion with a secondary system that requires the reviewer to calculate a total score based on these weighted measures. QOCI ascribes a more standard, nonweighted system to assessing course quality; however, it also requires that the reviewer go through 23 pages of criteria and rate each on a three-point scale.

Thus, the UNK instrument needed to be a hybrid of these two ideas: short enough to be completed in a relatively small period of time, and comprehensive enough to ensure that certain quality standards were addressed. Eventually, a simple complete/not complete checklist format was used, instead of a rubric-style rating system. This system made it much faster to complete than trying to assign a level of skill to each criterion. It also allowed the faculty to see what was needed for a quality course without having to read in-depth rationale for why a particular criterion was important, and read through examples of what was considered to be unsatisfactory versus excellent, and ratings in between. Although not as comprehensive, this system also allowed the faculty to take ownership of their own 
work, as it relied on their experience as instructors to determine which factors constituted the level of quality. This relies on the faculty (with additional help from an instructional designer, when needed) to bring their experience with teaching to the instrument.

\section{Addressing Multiple Faculty Skill Levels}

Online courses are constantly in a state of change. As new content, technology, and resources arrive, courses must be changed to reflect the current state of the materials and of the resources available to the faculty who develop these courses. eCampus continually offers new technology and resources to assist faculty in the development and teaching of online courses. Faculty at UNK also have different levels of expertise with online education. Therefore, the instructional design team felt that one inclusive rubric would not satisfy the needs of all faculty.

To ameliorate the situation, instructional designers decided to break the instrument up into three separate instruments reflecting a higher skill level for each successive version. The first instrument would cover the basics of building an online course for the first time. This covered basics like course overview materials, basic navigation, technical support, course management, grading, and assessment.

The second rubric was built to function for the first revision of the course. When faculty were preparing to teach the course again, they would use the second rubric to add more features and raise the quality of the course. Criteria represented in the second rubric included broader use of multimedia, chunking materials, inclusion of rubrics, more depth in interaction and discussion, and more access to resources.

The final rubric covered more advanced areas, such as full ADA compliance, multiple learning methods, and more advanced materials to foster student-content interaction.

\section{Compliance with Union Contract}

One of the issues the instructional designers encountered when developing the online course evaluation instrument was the faculty union contract at UNK. The contract does not allow the evaluation of faculty because of academic freedom. Thus, faculty are allowed to develop their courses in whatever manner they wish. Balancing course quality with academic freedom was the key idea in creating a checklist instead of a rubric.

Since faculty at UNK cannot be directly evaluated, the checklist format, at the very least, allowed faculty to see some of the basic criteria that go into a quality course. This method is far less intrusive than an instrument that would tell them they had failed to create a quality course. Instead of showing faculty that they do not have a quality course, it shows where they may have missed items that can be included to create a quality course. While this system may not be perfect, it was the best that could be created to comply with the union contract and also ensure a level of quality. The use of the word "rubric" versus "checklist" will be discussed further in the following section.

\section{Faculty Buy-In}

When the first draft of the instrument was finished, it was necessary to gain the support of the key stakeholders in online course development. This meant that eCampus needed support from faculty on the use of the instrument. The logical place to start was the UNK Faculty Senate. Rather than take the instrument to the full senate, it was presented to the eCampus committee to gain support, resolve issues, and gain feedback.

The initial presentation of the UNK Online Course Rubric to the eCampus Faculty Senate committee was in late 2006. The committee members were given 
copies of the rubric and asked to give their feedback on the rubric as a whole and on each of the individual criteria. The reviews were mostly positive, but some issues needed to be addressed.

The most strenuous arguments against the instrument in the form of a rubric were due to factors associated with academic freedom and the union contract. Committee members expressed concern over using a rubric to evaluate faculty: "While I think the rubric is comprehensive, I'm concerned that using a rubric violates our academic freedom." The general consensus was that the Union Contract did not allow for faculty to be assessed in this manner.

Several members of the committee were adamantly against using an evaluation rubric. One faculty member vehemently stated, "I don't use rubrics in my classes, why should I have to use one to evaluate my online course?" This statement reflected the attitudes of many faculty on the UNK campus at that time. Online education was still relatively new, and there was push-back about assessing teaching. This has changed over the past several years, but the legalities have remained the same. It should also be noted that there were, and still are, some faculty who resent having instructional designers with master's degrees evaluating the work of those with doctorates.

After further debate, the committee decided to change the rubric to a selfassessment instrument in the form of a checklist. While not ideal, this solution also created more buy-in from the faculty. At this point, the rubric officially became a checklist.

The members of the eCampus Faculty Senate Committee gave further input on minor changes in wording. These changes were considered, and then most were implemented, as none of them caused the criteria to change significantly. Some examples include the use of "learning activities" instead of "assessment," the inclusion of "modules" instead of "units" to refer to learning units, and adding "provided software" to a statement about freely available downloads. Afterward, the instrument received approval to move forward to the full Faculty Senate for a vote on implementation. The Online Course Checklist was approved by the Faculty Senate for use at UNK in the spring of 2007.

\section{Testing the Instrument}

Once the checklist was approved for use, a testing phase was initiated to determine if the instrument was useable, both by the instructional designers as a review instrument and by the faculty as a self-assessment. The time-intensive nature of the testing process for the checklist did not allow for a quantitative assessment of the instrument. Instead, the testing process was qualitative. The initial testing phase was an informal process of using the checklist during online course reviews and consultations. This worked as a self-selecting process where the first faculty to come for a consultation or course review were asked to use the checklist as part of the process. A total of 17 faculty members participated in the testing phase and provided feedback. Additional faculty teaching online were asked to review the checklist on their own to assess its usability as a self-assessment tool; these included members of the eCampus Faculty Senate Committee.

Initial reaction by the faculty was positive. The checklist helped to identify areas in their courses that were deficient and allowed them to revise their navigation and content to reflect a more user friendly experience for both the students and the faculty. The most common areas in the anecdotal evidence from part one of the checklist were those of navigation issues and the availability of resources. The second checklist showed the two criteria most commonly missed were "chunking" of materials and consistent use of navigational cues. The most common issue found when using the third checklist was the lack of proper ADA compliance.

Feedback on the checklist was not totally positive. A few faculty members voiced concerns about academic freedom, which was a common thread running through the creation process of the checklist. Some faculty were not happy about 
having a set of standards applied to their teaching. The use of the checklist to ensure quality was seen as an affront to their ability as instructors, even though the transition to an online format created new issues that they had not encountered in their face-to-face courses. The addition of a technical aspect, while seen as a threat, did not register as an area that some faculty felt needed any oversight.

One of the more common issues was that of length. Some felt that the instrument was too long to be used as a self-evaluation. This reinforced the idea to split the checklist into three separate parts, instead of presenting it as a whole instrument. After a review of the criteria, it was decided that, while there would be some complaints from faculty, the comprehensive nature of the instrument should stay the same, and none of the criteria would be eliminated. This also reinforced the instructional designers' choice not to use the off-the-shelf instruments reviewed initially.

\section{Revision of the Instrument and Deployment}

Once the testing process was completed, the checklist was revised to reflect some of the concerns. The checklists did not change greatly during the revision process; mainly, language was revised and items were moved around in the individual checklists and between checklists. Some criteria were rewritten to be more specific, and others were moved to the more advanced checklists and viceversa.

Once the revision was complete, it was necessary to deploy the checklists for use by the faculty and the instructional designers. The checklists were initially deployed on the eCampus website providing easy access to those who wanted to use it. An announcement regarding the availability of the checklists was sent to the entire campus via email. In addition to these electronic distribution methods, several information and training sessions were held to demonstrate and discuss the checklists with faculty. Finally, any faculty member who applied for a stipend to create an online course was sent a copy of the initial checklist via campus mail.

It is worth noting that the three checklists have recently been reduced to two. After several years of use, it was decided that the general level of expertise of the UNK faculty had grown enough to move some of the more advanced criteria to the first and second checklists. This left only a few criteria on the third checklist, so these were moved to the second checklist as well. This revision of the original instruments was also the impetus for writing this case study.

\section{Integration with Other Resources}

One of the initial outcomes of the testing and revision phase of the project was the need to integrate the checklist with other resources. Specifically, the Online Course Template was developed to give faculty a starting point for their classes and add in resources that many would not include in their course design.

The course template adds a Unit/Module structure to the traditional Blackboard shell and allows faculty to break up their content over several areas, instead of putting it all together in one folder. This creates an easier to understand and less confusing navigation structure for students to follow.

These particular features were addressed in several of the checklist sections. The use of these review standards in the checklist tied it to the template. Many of the criteria from the first checklist were tied directly to the template. This reinforced the standards and also made it easier for faculty to comply with the checklist criteria. This also allowed the instructional designers to perform a course review in less time, provided the faculty member had used the template in their course. Tying together the checklist and template also promoted the resources available to faculty across the disciplines. 


\section{Key Takeaways}

Building a course evaluation instrument can take large amounts of time and resources. Some best practices to help reduce this time are as follows:

- Use a pre-built instrument if it fits the needs of the campus.

- Review several instruments and apply them to a few courses before deciding what to use.

- If creating an instrument, start with instruments that fall under Creative Commons, rather than starting from scratch

- Identify the three or four most important issues that must be addressed and start with these.

- $\quad$ Once the most important issues are addressed and complete, move to the next set.

- Make sure that the instrument is easy to use and has language that does not confuse the reader. Involve faculty (and union if there is one on campus) to create a higher level of faculty buy-in.

- Test, test, test. There is no substitute for testing the instrument on multiple courses with multiple reviewers. Some of these reviewers should be faculty.

- $\quad$ Align the instrument with training and other resources.

\section{Conclusion}

An online course evaluation instrument is a critical component to any successful online course/program/institution. While prebuilt instruments can be quickly deployed, they may not properly serve the local campus community. Careful review of these instruments is needed before making any decision about creating a specific instrument for a campus. This may take time and resources, but it will create a more successful faculty, which in turn, creates a more successful student population. Tailoring an instrument to a specific university or college can be an excellent use of resources, if done with care and thought.

\section{Recommendations}

While reaction to the Online Course Checklist has been mostly positive, some issues should be addressed in the future. These include, but are not limited to, creating a separate actionable checklist for proactive development, recoding/grouping the criteria to make the checklist more useable, and revising the checklist to include newer technology and pedagogy skills.

The Online Course Checklist has been a useful evaluative tool for online courses at UNK. As an actionable tool for course development, there are some doubts as to its efficacy. The specific nature of the criteria makes the checklist better for reactive changes to courses. A

Make sure that the instrument is easy to use and has language that does not confuse the reader. Involve faculty (and union if there is one on campus) to create a higher level of faculty buy-in.

smaller instrument, with broader categories and fewer granular items, might be more useful as a tool for initial creation of courses. This type of instrument would create a roadmap for those creating a course for the first time.

Another issue is that the checklist has not been updated recently. Developments in technology and learning research may necessitate the revision of the instrument to reflect current standards and best practices. Most notably, new collaborative technology to facilitate interaction, the expanded use of interactive content to engage students, and the greater role of both in-house and professional video as a means of instruction and engagement. This should be an ongoing process, as a checklist of this nature should be a living document that reflects the current state of online education. 


\section{References}

Allen, I. E., \& Seaman, J. (2014). Grade change: Tracking online education in the United States. Retrieved from the Online Learning Consortium website: http://www.onlinelearningsurvey.com/rep orts/gradechange.pdf

Borgemenke, A. J., Holt, W. C., \& Fish W. W. (2013). Universal course shell template design and implementation to enhance student outcomes in online coursework. Quarterly Review of Distance Education, 14(1), 17-23.

Borup, J., West, R. E., \& Graham, C. R. (2012). Improving online social presence through asynchronous video. Internet and Higher Education, 15(3), 195-203.

Brindley, J. E., Blaschke, L. M., \& Walti, C. (2009). Creating effective collaborative learning groups in an online environment. International Review of Research in Open and Distance Learning, 10(3), 1-18. Retrieved from http://www.irrodl.org/index.php/irrodl/art icle/view/675/1313

Caplan, D., \& Graham, R. (2004). The development of online courses. Theory and Practice of Online Learning, 175.

Castle, S. R., \& McGuire, C. J. (2010). An analysis of student self-assessment of online, blended, and face-to-face learning environments: Implications for sustainable education delivery. International Education Studies, 3(3), 3640.

Chen, L. (2010). Web-based learning programs: Use by learners with various cognitive styles. Computers \& Education, 54(4), 1028-1035 doi:10.1016/j.compedu.2009.10.008

Cho, M., \& Cho, Y. (2014). Instructor scaffolding for interaction and students' academic engagement in online learning: Mediating role of perceived online class goal structures. Internet \& Higher Education, 21, 25-30. doi:10.1016/j.ineduc. 2013.10.008
DeCesare, J. (2014). The expanding role of online video in teaching, learning, and research. Library Technology Reports, 50(2), 5-11.

eCampus online course checklists. (2014). Retrieved from the University of Nebraska at Kearney eCampus Website:

http://www.unk.edu/academics/ecamp us/resources-info/faculty/onlinecourse-checklists.php

Gonzalez, C. (2010). What do university teachers think eLearning is good for in their teaching? Studies in Higher Education, 35(1), 61-78.

Graf, S., Liut, T.-C., \& Kinshuk. (2010). Analysis of learners' navigational behaviour and their learning styles in an online course. Journal of Computer Assisted Learning, 26(2), 116-131.

Guidelines from the Quality Matters rubric. (2009, October 1). Distance Education Report, 13(19), 5,7.

Havice, P. A., Davis, T. T., Foxx, K. W., \& Havice, W. L. (2010). The impact of rich media presentations on a distributed learning environment engagement and satisfaction of undergraduate students. Quarterly Review of Distance Education, 11(1), 53-58.

Hillman, S., \& Corkery, M. (2010, November) University infrastructural needs and decisions in moving towards online delivery programmes. Journal of Higher Education Policy and Management, 32(5), 467-74.

Hoffman, G. L. (2012) Using the Quality Matters rubric to improve online cataloging courses. Cataloging \& Classification Quarterly, 50(2-3), 15871.

Holding on to quality during rapid expansion. (2011, August 1). Distance Education Report, 15(15), 5-6. 
Hosie, P., Schibeci, R., \& Backhaus, A. (2005, October). A framework and checklists for evaluating online learning in higher education. Assessment \& Evaluation in Higher Education, 30(5), 539-553.

doi: $10.1080 / 02602930500187097$

Instructional designer's guide to working with faculty. (2006, February 1). Distance Education Report, 8(3), 8, 6.

Khan, S., \& Chishti, S. (2012) Effects of staff training and development on professional abilities of university teachers in distance learning systems. Quarterly Review of Distance Education, 13(2), 87-94.

Lee, M. J. W., \& Chan, A. (2007). Pervasive, lifestyle-integrated mobile learning for distance learners: An analysis and unexpected results from a podcasting study. Open Learning: The Journal of Open and Distance Learning, 22(3), 201-218.

Lorenzetti, J. (2009). Developing faculty competency in online pedagogy. Distance Education Report, 13(18), 58.

Metros, S. E., \& Hedberg, J. G. (2002). More than just a pretty inter(face) The role of the graphical user interface in engaging elearners. The Quarterly Review of Distance Education, 3(2), 191-205.

Miller, J. M. (2012). Finding what works online: Online course features that encourage engagement, completion, and success (Doctoral dissertation). Retrieved from California State University Northridge ScholarWorks website:

http://scholarworks.csun.edu/handle/1 0211.2/1062

Murray, M., Pérez, J., Geist, D., Hedrick, A., \& Steinbach, T. (2012). Student interaction with online course content: Build it and they might come. Journal of Information Technology Education, 11, 125-140.
Orde, B. J., Andrews, J., Awad, A., Fitzpatrick, S., Klay, C., Lie, C., Whitney, J. (2001). Online course development: Summative reflections. International Journal of Instructional Media, 28(4), 397-403.

Orr, R., Williams, M. R., \& Pennington, K. (2009). Institutional efforts to support faculty in online teaching. Innovative Higher Education, 34(4), 257-268. doi:10.1007/s10755-009-9111-6

Patterson Lorenzetti, J. (2007, November 15). Tool of the trade: Using the QOCI evaluation rubric. Distance Education Report, 11(22), 5, 7-8.

Poole, Dawn M. (2000). Student participation in a discussion-oriented online course: A case study. Journal of Research on Computing in Education, $33(2), 162-77$.

Power, M. (2008). A dual-mode university instructional design model for academic development. International Journal for Academic Development, 13(1), 5-16. doi: $10.1080 / 13601440701860185$

Quality Matters rubric. (n.d.). Retrieved from Quality Matters: https://www.qualitymatters.org/rubric

Quality Online Course Initiative rubric. (n.d.). Retrieved from Illinois Online Network:

http://www.ion.uillinois.edu/initiatives/qo ci/rubric.asp

Rahm-Barnett, S., \& Donaldson, D. P. (2008, March 1). 5-4-3-2-1 - Countdown to course management. Distance Education Report, 12(5), 3, 7.

Rubric for Online Instruction. (n.d.). Retrieved from California State University, Chico Website: http://www.csuchico.edu/roi/

Schiefelbein, J. (2011, March). Media richness and communication in online education. Online Classroom, 1-5. 
Singer, B. (2008). Online professional development: Combining best practices from teacher, technology and distance education. Journal of In-Service Education, 34(2), 205-218.

Sung, E., \& Mayer, R. E. (2012). Affective impace of navigational and signaling aids to e-learning. Computers in Human Behavior, 28, 473-483.
With Seton Hall's Course Template, All Faculty Are Champions. (2011). Distance Education Report, 15(7), 1-8.

Steven McGahan is an Assistant Director for Technology and Instructional Design Specialist at the University of Nebraska at Kearney's eCampus Division. Steven has 11 years of experience in higher education and holds a Bachelor's of Science in Multimedia and a Master's of Science in Education from the University of Nebraska at Kearney. He also teaches for the Department of Computer Science and Information Technology at UNK. His research interests include online education, eTextbooks, social media, and legal issues with online media.

Christina M. Jackson, APR, EdD teaches strategic communication and design in the Department of Communication at the University of Nebraska at Kearney. Her research areas include crisis communication, social media, healthcare communication and pedagogy. Jackson received her BS in mass communication from South Dakota State University. She received a MA in mass communication, an EdS in technology for education and training, and EdD in educational administration from the University of South Dakota. She holds the Accreditation in Public Relations $(A P R)$ designation.

Karen Premer is an Assistant Director for Marketing and Instructional Design Specialist at the University of Nebraska at Kearney's eCampus Division. She received her Bachelor of Science in Education degree and her Master of Science in Education from the University of Nebraska at Kearney. In addition to her current position Karen is an adjunct professor with the Industrial Technology Department where she teaches Communicating through Technology online. 